\title{
Influence of $\beta$-Stabilizers on the $\alpha-\mathrm{Ti} \rightarrow \omega$-Ti Transformation in Ti-Based Alloys
}

\author{
Askar Kilmametov 1,2, Alena Gornakova ${ }^{3}$, Mikhail Karpov ${ }^{3}$, Natalia Afonikova ${ }^{3}$, \\ Anna Korneva ${ }^{4}$, Pawel Zięba ${ }^{4}\left(\mathbb{D}\right.$, Brigitte Baretzky ${ }^{1}$ and Boris Straumal 1,2,3,5,* \\ 1 Institute for Nanotechnology, Karlsruhe Institute of Technology (KIT), Hermann-von-Helmholtz-Platz 1, \\ 76344 Eggenstein-Leopoldshafen, Germany; askar.kilmametov@kit.edu (A.K.); \\ brigitte.baretzky@kit.edu (B.B.) \\ 2 Scientific Center in Chernogolovka, Russian Academy of Sciences, Lesnaya str. 9, \\ 142432 Chernogolovka, Russia \\ 3 Institute of Solid State Physics, Russian Academy of Sciences, Ac. Ossipyan str. 2, \\ 142432 Chernogolovka, Russia; alenahas@issp.ac.ru (A.G.); karpov@issp.ac.ru (M.K.); \\ natasha@issp.ac.ru (N.A.) \\ 4 Institute of Metallurgy and Materials Science, Polish Academy of Sciences, Reymonta St. 25, 30-059 Cracow, \\ Poland; a.korniewa@imim.pl (A.K.); p.zieba@imim.pl (P.Z.) \\ 5 National University of Science and Technology «MISIS», Leninskii prosp. 4, 119049 Moscow, Russia \\ * Correspondence: straumal@issp.ac.ru; Tel.: +9-916-6768673
}

Received: 22 August 2020; Accepted: 9 September 2020; Published: 11 September 2020

\begin{abstract}
The development of next generation Ti-based alloys demand completely new processes and approaches. In particular, the Ti-alloys of next generation will contain not only $\alpha$-Ti and $\beta$-Ti phases, but also small amounts of $\omega$-phase and intermetallic compounds. The $\beta \rightarrow \omega$ phase transformation induced by high-pressure torsion (HPT) has been studied in detail recently. In this work, we investigated the HPT-induced $\alpha \rightarrow \omega$ phase transformation. For this purpose, we added various $\beta$-stabilizers into $\alpha$-Ti matrix of studied Ti-alloys. Ti-alloys with $4 \% \mathrm{Fe}, 2 \% \mathrm{Cr}, 3 \% \mathrm{Ni}$, and $4 \%$ Co (wt. \%) have been annealed at the temperatures below their point of eutectoid decomposition, from $\beta$-Ti to $\alpha$ - Ti, and respective intermetallics ( $\mathrm{TiFe}, \mathrm{Ti}_{2} \mathrm{Co}, \mathrm{Ti}_{2} \mathrm{Ni}, \mathrm{TiCr}_{2}$ ). Volume fraction of HPT-driven $\omega$-phase (from $\leq 5$ up to $\sim 80 \%$ ) depended on the amount of alloying element dissolved in the $\alpha$-matrix. Evaluation of lattice parameters revealed accelerated mass transfer during HPT at room temperature corresponding to bulk diffusion in $\alpha$-Ti at $\sim 600{ }^{\circ} \mathrm{C}$.
\end{abstract}

Keywords: Ti-alloys; $\alpha$-Ti $\rightarrow \omega$-Ti transformation; $\beta$-stabilizers; high-pressure torsion; mass transfer

\section{Introduction}

The development of next generation Ti-based alloys demand completely new processes and approaches. In particular, the Ti-alloys of next generation will contain not only $\alpha$-Ti and $\beta$-Ti phases, but also small amounts of $\omega$-phase and intermetallic compounds. Such phase changes can be initiated, for example, by high-pressure torsion (HPT) [1-3]. Titanium and Ti-alloys (similar to Zr- and Hf-based ones) can exist in three allotropic modifications, namely low-temperature hexagonal closely packed (hcp) $\alpha$-phase, high-temperature body-centered cubic (bcc) $\beta$-phase, and hexagonal high-pressure $\omega$-phase [4-13]. If the applied high pressure is combined with shear deformation, the pressure required for $\alpha$-Ti $\rightarrow \omega$-Ti transformation can be substantially reduced [14-16]. Under such high-pressure torsion (HPT) conditions, the additional driving force implies shear deformation in (0001)- $\alpha$ crystallographic slip systems. As a result, the deformation texture develops, favoring the subsequent athermal (martensite) $\alpha$-Ti $\rightarrow \omega$-Ti transformation, and the orientation relationship between $\alpha$ - and $\omega$-phases exactly correlates with theoretically predicted pathways for $\alpha$-Ti $\rightarrow \omega$-Ti transformation [5]. Doping 
titanium with the atoms of transition elements, which are rich in d-electrons, changes the electron structure of the alloy. If the concentration of d-electrons increases with alloying, it can be considered as the equivalent of external pressure. It facilitates, in turn, the formation of the $\omega$-phase [7,17]. Such an effect was actually observed in experiments $[18,19]$. Recently, the HPT-driven formation of the $\omega$-phase in $(\alpha+\beta)$ or $\beta$-Ti alloys was found to be dependent on the amount of alloying element [20]. The solubility of $\beta$-stabilizers in $\alpha$-Ti is much lower than in $\beta$-Ti. The theory predicts that impurities can change the energy barrier for the $\alpha \rightarrow \omega$ pathway [17]. To our best knowledge, there are no systematic experimental studies of the HPT-driven $\alpha \rightarrow \omega$ transition in Ti-based alloys in the absence of $\beta$-Ti. Moreover, an estimation of HPT-driven mass transfer appears to operate in $\alpha$-Ti based alloys. Thus, these are the main objectives of the given work. The $\beta \rightarrow \omega$ phase transformation induced by high-pressure torsion (HPT) has been studied in detail recently [20]. In this work, we investigated the HPT-induced $\alpha \rightarrow \omega$ phase transformation. For this purpose, we added various $\beta$-stabilizers into $\alpha$-Ti matrix of studied Ti- alloys.

\section{Materials and Methods}

Titanium alloys with $4 \% \mathrm{Fe}, 2 \% \mathrm{Cr}, 3 \% \mathrm{Ni}$, and $4 \% \mathrm{Co}$ (wt. \%) were manufactured using induction melting in vacuum from the starting components, with a purity of $99.95-99.99 \%$ in the form of ingots, with a diameter of $10 \mathrm{~mm}$. Initial metallic components have been manufactured by VSMPO-AVISMA, Verkhnyaya Salda, Russia (titanium), Oskol electrometallurgical plant, Staryi Oskol, Russia (iron), POLEMA, Tula, Russia (chromium), RedMetSplav, Ekaterinburg, Russia (nickel, cobalt). They were then spark cut into $0.7 \mathrm{~mm}$ thick disks. These disks were sealed in evacuated quartz ampoules with a residual pressure of $4 \times 10^{-4} \mathrm{~Pa}$. Ampoules with samples were annealed at temperatures of $400{ }^{\circ} \mathrm{C}$, $2472 \mathrm{~h} ; 500{ }^{\circ} \mathrm{C}, 1176 \mathrm{~h} ; 630{ }^{\circ} \mathrm{C}, 1000 \mathrm{~h} ; 650{ }^{\circ} \mathrm{C}, 1100 \mathrm{~h} ; 670{ }^{\circ} \mathrm{C}, 178 \mathrm{~h}$ (the alloy with Co); $600{ }^{\circ} \mathrm{C}$, $2774 \mathrm{~h}$ (alloys with $\mathrm{Co}, \mathrm{Cr}$ and $\mathrm{Ni}$ ); $470{ }^{\circ} \mathrm{C}, 750 \mathrm{~h}$ (alloy with $\mathrm{Fe}$ ). These temperatures were below the eutectoid temperatures $T_{\text {eut }}$ of the $\beta$-phase decomposition at the corresponding phase diagrams [21-23]. The content of $\mathrm{Fe}, \mathrm{Ni}$, and $\mathrm{Cr}$ in the $\alpha$-phase did not exceed $\sim 1.0 \mathrm{wt} . \%$ due to the low solubility of these elements in $\alpha$-Ti. Co has the highest solubility in $\alpha$-Ti among studied $\beta$-stabilizers. Therefore, $\mathrm{Ti}-4 \mathrm{wt} . \% \mathrm{Co}$ alloy was annealed in a wide temperature range, from 400 to $670{ }^{\circ} \mathrm{C}$, in order to alter Co concentration in $\alpha$-Ti from almost zero to a maximum of about $1.7 \mathrm{wt} . \%$ near $T_{\text {eut }}=685^{\circ} \mathrm{C}$. After annealing, the samples were quenched in water (the ampoules were broken). Then, the samples were subjected to HPT in a Bridgman anvil chamber (Walter Klement GmbH, Lang, Austria) at room temperature; pressure $7 \mathrm{GPa}, 5$ anvil revolutions with angular rate of $1 \mathrm{rpm}$. Samples for structural studies were then mechanically ground and polished on diamond paste with a grain size of down to $1 \mu \mathrm{m}$. Samples after HPT were cut out at a distance of $3 \mathrm{~mm}$ from the center of the deformed disk. The resulting samples were studied using scanning electron microscopy (SEM) and X-ray microanalysis on a Tescan Vega TS5130 MM instrument (Tescan Orsay Holding a.s., Brno, Czech Republic) equipped with a LINK energy dispersive spectrometer manufactured by Oxford Instruments Industrial Ltd., Abingdon, Oxon, UK, and FEI ESEM XL30 scanning electron microscope (FEI, Hillsborough, OR, USA) equipped with Genesis EDS spectrometer (FEI, Hillsborough, OR, USA). X-ray diffraction (XRD) patterns were obtained in Bragg-Brentano geometry on a Philips X'Pert powder diffractometer (Koninklijke Philips N.V., Amsterdam, The Netherlands) using Cu-K $\alpha$ radiation at $45 \mathrm{kV}$ and $40 \mathrm{~mA}$ for 30-155 degrees angular range and $120 \mathrm{~s}$ per the step of 0.02 degrees. The lattice parameter was determined using the Fityk program [24]. The alloy phases were identified by comparison with X'Pert HighScore Panalytical phase bank data. Transmission electron microscopy (TEM) was performed on a Tecnai G2 FEG Super-Twin (200 kV) microscope (FEI, Hillsborough, OR, USA) equipped with an energy dispersive spectrometer manufactured by EDAX (AMETEK, Inc., Berwyn, PA, USA). Thin-film samples for TEM were made by electro polishing on an electrolyte D2 device manufactured by Struers Inc. (Cleveland, OH, USA). 


\section{Results}

Figure 1 presents the SEM micrographs for the Ti-4wt.\% Co alloy preliminary annealed at $600{ }^{\circ} \mathrm{C}$ (2774 h) before HPT (a) and after HPT (b). The $\alpha$ - or $(\alpha+\omega)$-matrix appears dark-grey. $\mathrm{The} \mathrm{Ti}_{2} \mathrm{Co}$ intermetallic particles appear light grey. After $\mathrm{HPT}$, the $\mathrm{Ti}_{2} \mathrm{Co}$ particles remain almost unchanged (due to their high hardness, like in $\mathrm{Cu}$-based alloys [25]). Figure 1 also presents bright-field (Figure 1c) and dark-field (Figure 1d) TEM micrographs, together with the selected area diffraction pattern (Figure 1e) for the $(\alpha+\omega)$ matrix of the Ti-4wt.\% Co alloy after HPT preliminary annealed at $600{ }^{\circ} \mathrm{C}(2774 \mathrm{~h})$ after HPT. The circle in Figure 1e marks the reflexes used for the dark-field image in Figure 1d. The grains of the $\alpha$ - and $\omega$-phases are visible in the microstructure. Prior to HPT, the grain size of the $\alpha$-phase was several microns [26,27]. HPT leads to a strong refinement of the $\alpha$-phase structure, and the grain size in the $\alpha$-phase after HPT does not exceed $200 \mathrm{~nm}$. The grains of the $\omega$-phase formed during HPT are even smaller; their size does not exceed $30 \mathrm{~nm}$.
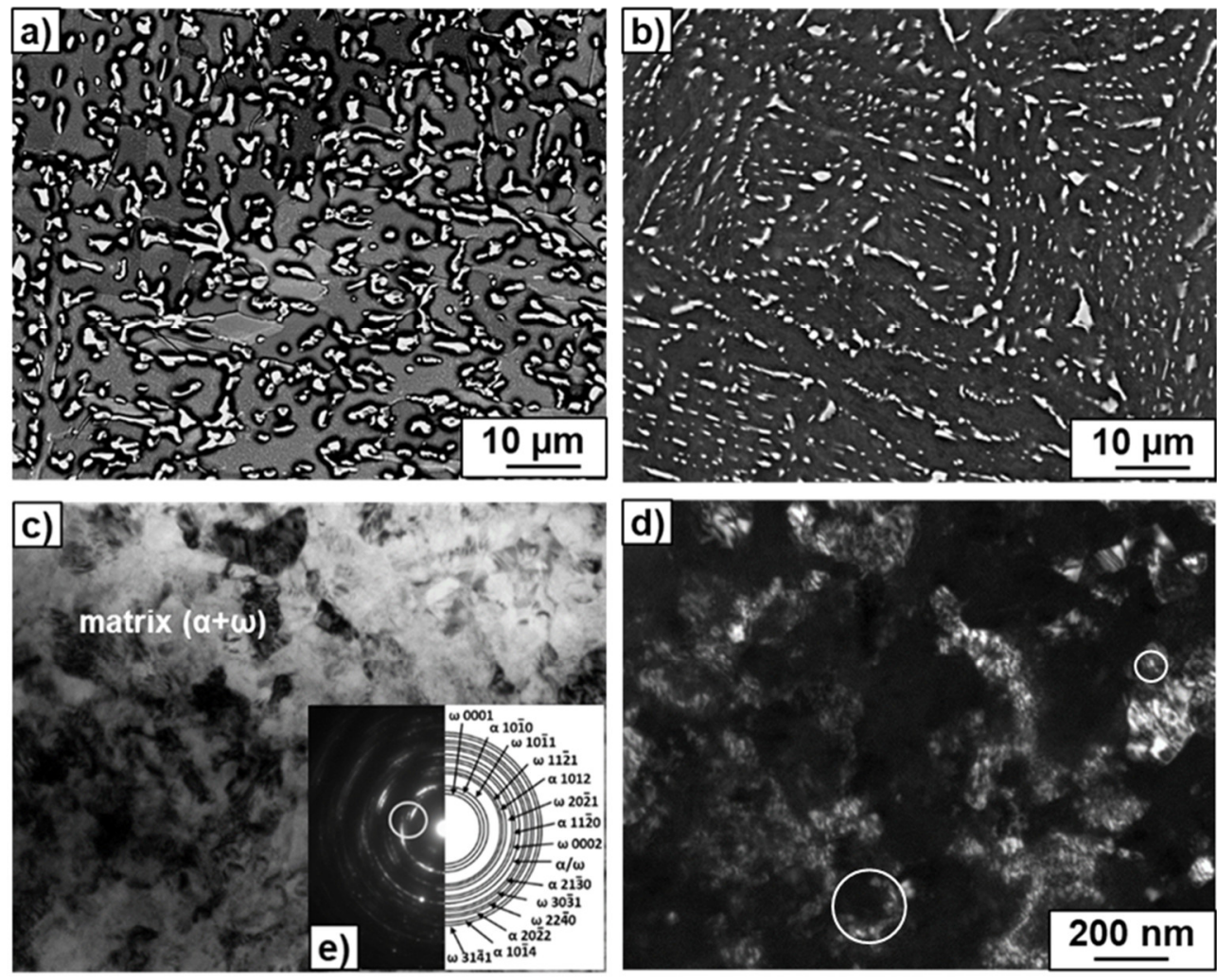

Figure 1. SEM micrographs for the Ti-4wt.\%Co alloy preliminary annealed at $600{ }^{\circ} \mathrm{C}(2774 \mathrm{~h})$ before high-pressure torsion (HPT) (a) and after HPT (b). Bright-field (c) and dark-field (d) TEM micrographs as well as the selected area diffraction pattern (e) for the $(\alpha+\omega)$ matrix in Ti-4wt.\% Co alloy preliminary annealed at $600{ }^{\circ} \mathrm{C}(2774 \mathrm{~h})$ after HPT. The circle in Figure 1e marks the reflections used for the dark-field image in Figure 1d. The circles in Figure 1d mark the example grains of $\alpha$-phase (dark grain, big circle) and $\omega$-phase (bright grain, small circle).

Figure 2a shows the XRD patterns for Ti-3wt.\%Ni (upper curve), Ti-2wt.\% Cr (middle curve), and $\mathrm{Ti}-4 \mathrm{wt}$.\% Co (lower curve) alloys annealed at $600{ }^{\circ} \mathrm{C}, 2774 \mathrm{~h}$ before HPT. They contain peaks of $\alpha$-Ti and respective intermetallics $\mathrm{Ti}_{2} \mathrm{Ni}, \mathrm{TiCr}_{2}$, or $\mathrm{Ti}_{2} \mathrm{Co}$ [21-23]. Figure $2 \mathrm{~b}$ shows the XRD patterns of same alloys after HPT. All of the peaks are substantially broadened due to the grain refinement. The $\alpha$-Ti peaks are present in all three patterns. In addition to them, a noticeable amount of the $\omega$-phase was detected (Figure 2b).

Figure 3 a shows the dependence of the $\omega$-phase volume fraction after HPT in Ti-4wt. \% Co samples on the annealing temperature (open circles). Relative amounts of alpha-, beta-, and omega-phases were 
estimated from the integrated peak intensities for the whole diffraction pattern. Pure polycrystalline titanium was used as reference. The point for pure $\alpha$-Ti is conditionally shown at $200{ }^{\circ} \mathrm{C}$. By very small addition of Co to $\alpha$-Ti, the volume fraction increases up to $80 \%$. With the increase of annealing temperature, the amount of $\mathrm{Co}$ in $\alpha$-Ti increases and the $\omega$-phase volume fraction decreases. It reaches zero slightly above $600{ }^{\circ} \mathrm{C}$ and stays at zero up to $T_{\text {eut }}=685^{\circ} \mathrm{C}$. The filled squares in Figure 3a show that the volume fraction of $\omega$-phase after HPT decreases, with increasing concentration of alloying element dissolved in $\alpha$-Ti before HPT.
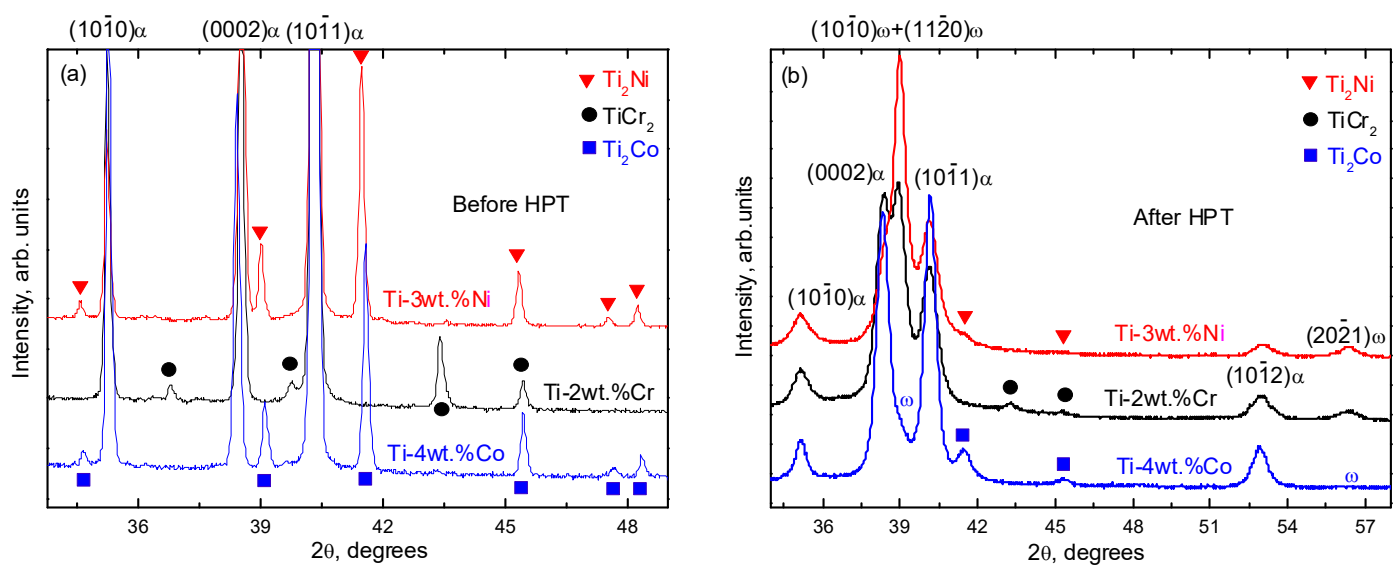

Figure 2. X-ray diffraction patterns of Ti-3wt.\% Ni (upper curves), Ti-2wt.\% Cr (middle curves), and Ti-4wt.\% Co (lower curves) annealed at $600{ }^{\circ} \mathrm{C}, 2774 \mathrm{~h}$ (a) before HPT and (b) after HPT.
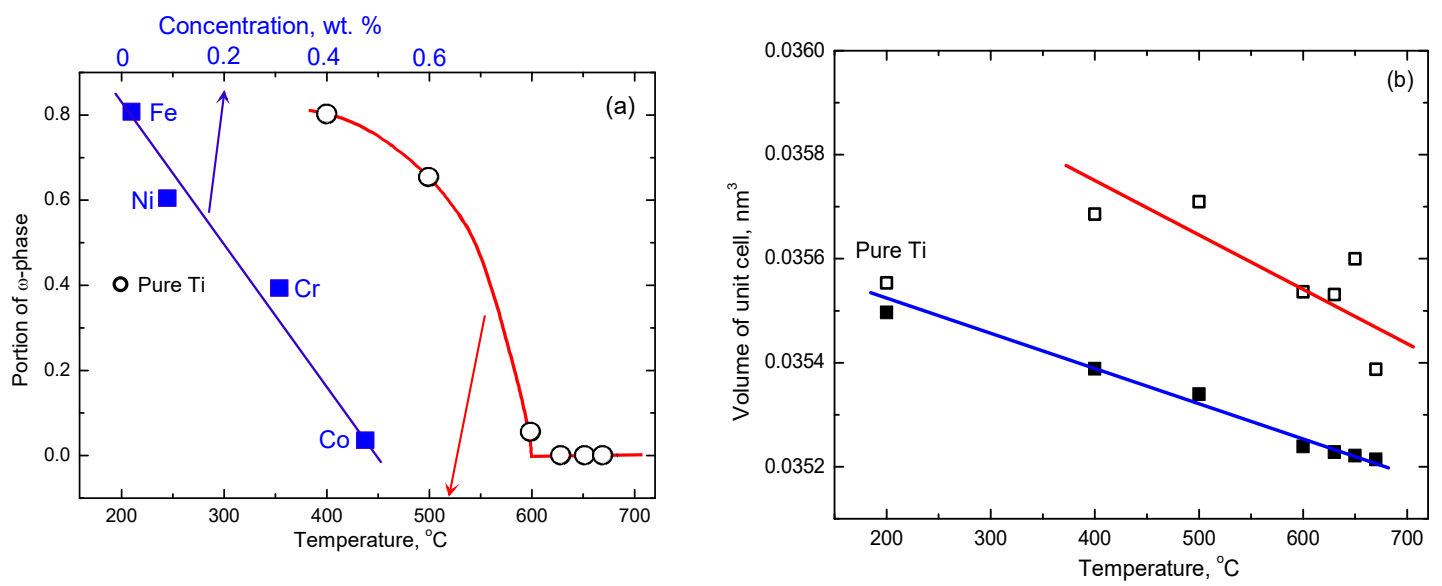

Figure 3. (a) The dependence of $\omega$-phase portion after HPT in Ti-4wt.\% Co alloy on temperature (open circles) and on concentration of $\beta$-stabilizers (blue solid squares). The values of $\omega$-phase portion for different $\beta$-stabilizers are measured at $600{ }^{\circ} \mathrm{C}$ for $\mathrm{Co}, \mathrm{Cr}, \mathrm{Ni}$, and at $470{ }^{\circ} \mathrm{C}$ for $\mathrm{Fe}$. (b) Temperature dependence of the crystal cell volume calculated from XRD patterns for $\alpha$-Ti in Ti-4wt.\% Co alloy before HPT (filled black squares) and after HPT (open squares). The volume of hexagonal unit cell of $\omega$-phase is equal to $\left(3^{0.5} a^{2} c\right) / 2$ where $a$ and $c$ are lattice parameters.

Figure $3 \mathrm{~b}$ shows the temperature dependences of the crystal unit cell volume for $\alpha$-Ti in Ti-4wt.\% Co alloy before HPT (filled black squares) and after HPT (open squares) calculated from XRD data. According to the Ti-Co phase diagram, the concentration of cobalt dissolved in the $\alpha$-Ti lattice increases with temperature from zero to about $1.7 \mathrm{wt} . \%$ close to the eutectoid transformation at $T_{\text {eut }}=685^{\circ} \mathrm{C}$ [21-23]. In this case, the volume of the $\alpha$-Ti unit cell decreases with increasing annealing temperature. Thus, in pure $\alpha-\mathrm{Ti}$, it is equal to $0.0355 \mathrm{~nm}^{3}$ and $0.0352 \mathrm{~nm}^{3}$ in the sample annealed at $670{ }^{\circ} \mathrm{C}$. After HPT, the unit cell volume for $\alpha$-Ti increases in all studied Ti-Co samples by about $0.5-1 \%$ and becomes compatible or even higher than that in pure titanium. We observed a similar 
phenomenon earlier in the case of the HPT of $\alpha^{\prime}$-martensites in Ti-Fe alloys [28]. These $\alpha^{\prime}$-martensites were obtained by quenching of $\beta$-Ti phase from high temperatures. Since the maximum solubility of iron in $\alpha$-Ti does not exceed $0.04 \mathrm{wt} . \%$ [22,23], all Ti-Fe samples quenched from high temperature $\beta$-region contained $\alpha^{\prime}$-martensite. The HPT of such $\alpha^{\prime}$-alloys also led to an increase in the volume of the crystalline cell, and these values became higher than in pure titanium [28]. We can explain this phenomenon in Ti-Fe alloys (and now in Ti-Co alloys) by the "purification" of the $\alpha^{\prime}$ - or $\alpha$-phase under the influence of HPT.

\section{Discussion}

It is known that $\omega$-phase strongly influences the mechanical properties of Ti-alloys [29-31]. Its formation was studied mainly for $(\alpha+\beta)$ or $\beta$-Ti alloys. Evidently, in case of $(\alpha+\beta)$-mixtures, the $\beta$-stabilizers are concentrated in the $\beta$-phase. Here, their amount might exceed several times the total concentration in the alloy, and for the $\alpha$-Ti, remains the minority of the alloying atoms. The studies of $\beta \rightarrow \omega$ martensite (or athermal) transformations revealed that alloying by atoms of transition elements lead to rapid transformation into $\omega$-Ti. It is because of rather close crystallography of $\beta$ - and $\omega$-phases. It is known that martensitic transformations need the special orientation relationships and can be driven by the shear strain [32-38]. Under HPT conditions, an optimal lattice matching between $\beta$ and $\omega$-phases in Ti-Fe alloys is revealed close to $4 \mathrm{wt} \% \mathrm{Fe}$ [20]. In the Ti-4 wt $\%$ Fe alloy, the $\beta \rightarrow \omega$ transformation is completed already at early stage of HPT deformation [20]. The HPT-driven $\alpha \rightarrow \omega$ or $\alpha^{\prime} / \alpha \rightarrow \omega$ phase transformations in Ti-based alloys also imply shear-type transition, which corresponds to the well-known orientation relationship between $\alpha$-Ti and $\omega$-Ti [4]. In this work, the initial state before HPT (Figure 2a) contained the $\alpha$-phase as a matrix (without any martensite) and the corresponding intermetallic compound ( $\mathrm{TiFe}, \mathrm{Ti}_{2} \mathrm{Co}, \mathrm{Ti}_{2} \mathrm{Ni}, \mathrm{TiCr}_{2}$ ).

Figure $2 \mathrm{~b}$ revealed the redistribution of the peak intensities after HPT. It clearly shows the evidence of deformation texture. Namely, the $(0,1-1,1)_{\alpha}$ and $(0,1-1,0)_{\alpha}$ peaks before HPT are higher than the $(0002)_{\alpha}$ one in all studied alloys (Figure 2a). During measurements of all XRD patterns before and after HPT, the incident beam was directed under same angle to the surface of flat HPT sample. After HPT, the intensity of $(0002)_{\alpha}$ peak becomes higher than that of $(0,1-1,1)_{\alpha}$ and $(0,1-1,0)_{\alpha}$ peaks (Figure $2 b$ ). Moreover, the $(0,1-1,1)_{\alpha}$ peak almost disappeared after HPT. This fact testified the development of strong shear texture in the $\alpha$-phase. It precedes the $\alpha \rightarrow \omega$ transition. This fact is in accordance with theoretical predictions where $(0001)_{\alpha}$ planes are parallel to $(0,1-1,1)_{\omega}$ or $(1,1-2,1)_{\omega}$ ones [4].

The increased intensity of the (0002)- $\alpha$ peaks testified the development of strong shear texture in the $\alpha$-phase. It precedes the $\alpha \rightarrow \omega$ transition. This fact is in accordance with theoretical predictions where $(0001)_{\alpha}$ planes are parallel to $(0,1-1,1)_{\omega}$ or $(1,1-2,1)_{\omega}$ ones [4]. If $\alpha$-Ti contains $\sim 0.04-0.5 w t . \%$ of $\beta$-stabilizer before HPT, the $\omega$-phase volume fraction after HPT decreases in the sequence $\mathrm{Fe} \rightarrow \mathrm{Ni} \rightarrow \mathrm{Cr} \rightarrow \mathrm{Co}$. Thus, it was estimated as $\sim 75-85 \%$ for $\mathrm{Ti}-\mathrm{Fe}, \sim 55-65 \%$ for $\mathrm{Ti}-\mathrm{Ni}, \sim 30-40 \%$ for $\mathrm{Ti}-\mathrm{Cr}$ and $\leq 5 \%$ for Ti-Co alloys (see Figure 3a). These experimental data were obtained in the equivalent processing conditions for different Ti-based alloys with the alloying metals of 4-th group. This fact means that the amount of alloying atoms in the $\alpha$-Ti matrix plays, most probably, a crucial role in HPT-induced formation of the $\omega$-phase. Even relatively small deviation in the alloying of the $\alpha$-phase modifies its stability regarding the $\alpha \rightarrow \omega$ martensite transformation. Moreover, the change of the annealing temperatures below $T_{\text {eut }}=685^{\circ} \mathrm{C}$, namely in the range of $400-670^{\circ} \mathrm{C}$ for Ti-Co alloy, allowed to control the Co concentration in the $\alpha$-Ti matrix. HPT-induced formation of the $\omega$-phase in Ti-Co alloy (Figure $3 \mathrm{~b}$ ) appeared in good correlation with the results regarding different alloying elements. Our experimental results confirm the theoretical calculations for the energies of $\alpha \rightarrow \omega$ pathways $[4,5]$. As authors of $[4,5]$ concluded, the $\alpha \rightarrow \omega$ phase transition is sensitive to small changes of the energy barriers and could be blocked or facilitated in dependence on different sort of impurities.

We have to underline that, in the present manuscript, we studied all samples at the same pressure of $7 \mathrm{GPa}$, and same strain (i.e., after $5 \mathrm{HPT}$ anvil revolutions). The studies investigating the formation of $\omega$-phase in pure Ti found that the fraction of $\omega$-phase in HPT-processed Ti increases also with 
straining (number of revolutions) and pressure between 3 and 6 GPa [15]. However, we observed in Ti-Co alloys that between 6 and 7 GPa the growth of the $\omega$-phase portion slows down [39]. The amount of $\omega$-phase indeed increases at the beginning of HPT process. However, it saturates after 2-3 anvil rotations together with grain size and torsion torque [20,40]. Thus, the initial instabilities during HPT evolve into the steady state [25,41-45]

It should be noted that decreased amount of the $\omega$-phase after HPT was also observed in Ti-Fe alloys with $0.5,1,2.2$ and $4 \mathrm{wt} . \% \mathrm{Fe}$, if the initial state consists of mostly $\alpha^{\prime}$-martensite in the $\left(\alpha / \alpha^{\prime}\right)$-phase mixture $[20,28]$. This happens in alloys with lower content of Fe, such as 0.5 and $1 \%$, annealed and quenched from $950{ }^{\circ} \mathrm{C}$. In the latter case, the amount of the $\omega$-phase appeared to be two times lower than in Ti-4wt.\%Fe alloy and could be caused by solubility of $\sim 0.04 \mathrm{wt} . \% \mathrm{Fe}$ in $\alpha^{\prime}$-martensite as well.

As was noticed above, and presented in our previous works [20,28], in addition to diffusionless (and relatively fast) $\alpha \rightarrow \omega$ transformations, the processes associated with accelerated mass transfer also occur under HPT influence. In order to describe the mass transfer driven by HPT in copper and aluminum alloys, we estimated the equivalent diffusion coefficient [25]. Now we perform similar estimations for mixing in a titanium alloy. In the initial state, the Ti-4wt.\% Co samples annealed near $T_{\text {eut }}$ contain the $\alpha$-phase with a low cobalt content and the $\mathrm{Ti}_{2} \mathrm{Co}$ intermetallic compound (Figure $3 b$ ). The grain size of the $\alpha$ - and $\mathrm{Ti}_{2}$ Co-phases is approximately $L=5 \mu \mathrm{m}[26,27]$. After deformation, the sample contains an $\alpha$-phase with a lower cobalt content (Figure $3 b$ ) and a grain size of approximately $200 \mathrm{~nm}$ (Figure 1). The time required to achieve this state is $t=300 \mathrm{~s}$. Using the simple formula $L=(D t)^{0.5}$ for the mass transfer by volume diffusion, we obtain an estimate for the volume diffusion coefficient $D=10^{-13} \mathrm{~m}^{2} \mathrm{~s}^{-1}$, which is necessary to obtain such a result of mixing and mass transfer. Volume diffusion of cobalt in $\alpha$-titanium occurs with such a coefficient $D=10^{-13} \mathrm{~m}^{2} \mathrm{~s}^{-1}$ at $600{ }^{\circ} \mathrm{C}$ [32]. Extrapolation of the data on the volume diffusion of iron in titanium to the temperature of the HPT $T_{\mathrm{HPT}}=30^{\circ} \mathrm{C}$ gives the value $D=10^{-25}-10^{-26} \mathrm{~m}^{2} \mathrm{~s}^{-1}$. Thus, under the influence of HPT in the alloy of titanium with cobalt, the accelerated mass transfer occurs at a rate of 12-13 orders of magnitude faster than the rate of ordinary thermal diffusion at room temperature (i.e., at the HPT temperature $T_{\mathrm{HPT}}=30^{\circ} \mathrm{C}$ ). We observed earlier the similar mass transfer, accelerated by HPT, in the study of HPT-driven competition between the decomposition of a solid solution and the dissolution of precipitates in copper alloys [25].

\section{Conclusions}

In summary, a number of Ti-based alloys with $4 \% \mathrm{Fe}, 2 \% \mathrm{Cr}, 3 \% \mathrm{Ni}$, and $4 \% \mathrm{Co}$ (wt. $\%$ ) have been annealed at the temperatures below their point of eutectoid transformation in order to achieve the mixture of $\alpha$-Ti matrix doped with respective $\beta$-stabilizers, elements of the fourth group, and intermetallics ( $\mathrm{TiFe}, \mathrm{Ti}_{2} \mathrm{Co}, \mathrm{Ti}_{2} \mathrm{Ni}, \mathrm{TiCr}_{2}$ ). The study of HPT-induced $\alpha \rightarrow \omega$ phase transformation revealed that the volume fraction of $\omega$-phase depends on the initial amount of alloying element in $\alpha$-phase. An increase of $\beta$-stabilizers concentration in the $\alpha$-Ti matrix before HPT from $\sim 0.04$ to $0.5 \mathrm{wt} . \%$ led to decrease of the $\omega$-Ti fraction after HPT from $\sim 80$ to $\leq 5 \%$. The increase of the Co amount up to $\sim 1.0 \mathrm{wt} . \%$ resulted in full suppression of the $\omega$-phase formation. An estimation of the equivalent diffusion coefficient was performed regarding HPT-driven mass transfer in Ti-based alloys at room temperature. It was found to be corresponding to bulk diffusion in $\alpha$-Ti at $\sim 600{ }^{\circ} \mathrm{C}$.

Author Contributions: Conceptualization, P.Z., B.B. and B.S.; methodology, A.K. (Askar Kilmametov) and N.A; validation, A.K. (Askar Kilmametov) and N.A.; formal analysis, M.K.; investigation, A.G. and A.K. (Anna Korneva); data curation, A.K. (Anna Korneva); writing-original draft preparation, B.B. and B.S.; writing-review and editing, M.K. and P.Z.; supervision, B.B. and B.S.; project administration, B.B.; funding acquisition, B.B and B.S. All authors have read and agreed to the published version of the manuscript.

Funding: This research was funded by the Russian Foundation for Basic Research (grants 18-33-00473 and 19-58-06002), the German National Research Society DFG (grants RA 1050/20-1, IV 98/5-1, HA 1344/32-1, FA 999/1-1), and the National Center for Science of the Polish Republic (grant OPUS 2017/27/B/ST8/010192).

Acknowledgments: This work was partially carried out within the framework of the state assignment of the Institute of Solid State Physics and the Chernogolovka Scientific Center of the Russian Academy of Sciences. 
Conflicts of Interest: The authors declare no conflict of interest.

\section{References}

1. Javanbakht, M.; Levitas, V.I. Phase field simulations of plastic strain-induced phase transformations under high pressure and large shear. Phys. Rev. B 2016, 94, 214104. [CrossRef]

2. Feng, B.; Levitas, V.I. Plastic flows and strain-induced alpha to omega phase transformation in zirconium during compression in a diamond anvil cell: Finite element simulations. Mater. Sci. Eng. A 2017, 680, 130-140. [CrossRef]

3. Pandey, K.K.; Levitas, V.I. In situ quantitative study of plastic strain-induced phase transformations under high pressure: Example for ultra-pure Zr. Acta Mater. 2020, 196, 338-346. [CrossRef]

4. Usikov, M.P.; Zilberstein, V.A. The orientation relationship between the $\alpha$ - and $\omega$ - phases of titanium and zirconium. Phys. Stat. Sol. A 1973, 19, 53-58. [CrossRef]

5. Trinkle, D.R.; Hennig, R.G.; Srinivasan, S.G.; Hatch, D.M.; Jones, M.D.; Stokes, H.T.; Albers, R.C.; Wilkins, J.W. New mechanism for the $\alpha$ to $\omega$ martensitic transformation in pure titanium. Phys. Rev. Lett. 2003, 91, 025701. [CrossRef] [PubMed]

6. Jamieson, J.C. Crystal structures of titanium, zirconium, and hafnium at high pressures. Science 1963, 140, 72-73. [CrossRef] [PubMed]

7. Sikka, S.K.; Vohra, Y.K.; Chidambaram, R. Omega phase in materials. Prog. Mater. Sci. 1982, 27, $245-310$. [CrossRef]

8. Feng, B.; Levitas, V.I.; Kamrani, M. Coupled strain-induced alpha to omega phase transformation and plastic flow in zirconium under high pressure torsion in a rotational diamond anvil cell. Mater. Sci. Eng. A 2018, 731, 623-633. [CrossRef]

9. Zhang, J.; Zhao, Y.; Rigg, P.A.; Hixson, R.S.; Gray, G.T., III. Impurity effects on the phase transformations and equations of state of zirconium metals. J. Phys. Chem. Solids 2007, 68, 2297-2302. [CrossRef]

10. Levitas, V.I. High pressure phase transformations revisited. J. Phys. Cond. Mat. 2018, 30, 163001. [CrossRef]

11. Srinivasarao, B.; Zhilyaev, A.P.; Pérez-Prado, M.T. Orientation dependency of the $\alpha$ to $\Omega$ plus $\beta$ transformation in commercially pure zirconium by high-pressure torsion. Scripta Mater. 2011, 65, 241-244. [CrossRef]

12. Levitas, V.I.; Chen, H.; Xiong, L. Lattice instability during phase transformations under multiaxial stress: Modified transformation work criterion. Phys. Rev. B 2017, 96, 05411. [CrossRef]

13. Zhang, J.; Zhao, Y.; Pantea, C.; Qian, J.; Rigg, P.; Hixson, R.; Gray, G.T.; Yang, Y.; Wang, L.; Wang, Y.; et al. Experimental constraints on the phase diagram of elemental zirconium. J. Phys. Chem. Solids 2005, 66, 1213-1219. [CrossRef]

14. Kilmametov, A.R.; Khristoforov, A.V.; Wilde, G.; Valiev, R.Z. X-ray studies of nanostructured metals processed by severe plastic deformation. Zeits. Kryst. 2007, 2, 339-344. [CrossRef]

15. Ivanisenko, Y.; Kilmametov, A.; Rösner, H.; Valiev, R.Z. Evidence of $\alpha$ to $\omega$ phase transition in titanium after high pressure torsion. Int. J. Mater. Res. 2008, 99, 36-41. [CrossRef]

16. Mazilkin, A.; Straumal, B.; Kilmametov, A.; Straumal, P.; Baretzky, B. Phase transformations induced by severe plastic deformation. Mater. Trans. 2019, 60, 1489-1499. [CrossRef]

17. Hennig, R.; Trinkle, D.R.; Bouchet, J.; Srinivasan, S.G.; Albers, R.C.; Wilkins, J.W. Impurities block the $\alpha$ to $\omega$ martensitic transformation in titanium. Nature Mater. 2005, 4, 129-133. [CrossRef]

18. Afonikova, N.S.; Degtyareva, V.F.; Litvin, Y.A.; Rabinkin, A.G.; Skakov, Y.A. Formation of high-pressure w-phase in titanium. Sov. Phys. Sol. State 1973, 15, 746-749.

19. Dey, G.K.; Tewari, R.; Banerjee, S.; Jyoti, G.; Gupta, S.C.; Joshi, K.D.; Sikka, S.K. Formation of a shock deformation induced $\omega$ phase in Zr 20 Nb alloy. Acta Mater. 2004, 52, 5243-5254. [CrossRef]

20. Kilmametov, A.; Ivanisenko, Yu.; Mazilkin, A.A.; Straumal, B.B.; Gornakova, A.S.; Fabrichnaya, O.B.; Kriegel, M.J.; Rafaja, D.; Hahn, H. The $\alpha \rightarrow \omega$ and $\beta \rightarrow \omega$ phase transformations in Ti-Fe alloys under high-pressure torsion. Acta Mater. 2018, 144, 337-351. [CrossRef]

21. Nash, P.; Choo, H.; Schwarz, R.B. Thermodynamic calculation of phase equilibria in the Ti-Co and Ni-Sn systems. J. Mater. Sci. 1998, 33, 4929-4936. [CrossRef]

22. Murray, J. (Ed.) Phase Diagrams of Binary Titanium Alloys; ASM International: Metals Park, OH, USA, 1987; 59p.

23. Murray, J. The Co-Ti (cobalt-titanium) system. Bull. Alloy Phase Diagr. 1982, 3, 74-86. [CrossRef] 
24. Wojdyr, M. Fityk: A general-purpose peak fitting program. J. Appl. Cryst. 2010, 43, 1126-1128. [CrossRef]

25. Straumal, B.B.; Kilmametov, A.R.; Baretzky, B.; Kogtenkova, O.A.; Straumal, P.B.; Lityńska-Dobrzyńska, L.; Chulist, R.; Korneva, A.; Zięba, P. High pressure torsion of $\mathrm{Cu}-\mathrm{Ag}$ and $\mathrm{Cu}-\mathrm{Sn}$ alloys: Limits for solubility and dissolution. Acta Mater. 2020, 195, 184-198. [CrossRef]

26. Straumal, B.B.; Korneva, A.; Kilmametov, A.R.; Lityńska-Dobrzyńska, L.; Gornakova, A.S.; Chulist, R.; Karpov, M.I.; Zięba, P. Structural and mechanical properties of Ti-Co alloys treated by the HPT. Materials 2019, 12, 426. [CrossRef]

27. Korneva, A.; Straumal, B.; Kilmametov, A.; Gondek, Ł.; Wierzbicka-Miernik, A.; Lityńska-Dobrzyńska, L.; Chulist, R.; Cios, G.; Zięba, P. Thermal stability and microhardness of metastable $\omega$-phase in the Ti-3.3at.\%Co alloy subjected to HPT. J. Alloys Compd. 2020, 834, 155132. [CrossRef]

28. Kilmametov, A.; Ivanisenko, Yu.; Straumal, B.B.; Mazilkin, A.A.; Gornakova, A.S.; Kriegel, M.J.; Fabrichnaya, O.B.; Rafaja, D.; Hahn, H. Transformations of $\alpha^{\prime}$ martensite in Ti-Fe alloys under HPT. Scr. Mater. 2017, 136, 46-49. [CrossRef]

29. Pang, E.L.; Pickering, E.J.; Baik, S.I.; Seidman, D.N.; Jones, N.G. The effect of zirconium on the $\Omega$ phase in Ti-24Nb-[0-8.Zr] (at.\%) alloys. Acta Mater. 2018, 153, 62-70. [CrossRef]

30. Kolli, R.P.; Devaraj, A. A review of metastable beta titanium alloys. Metals 2018, 8, 506. [CrossRef]

31. Xu, T.; Zhang, S.; Liang, S.; Cui, N.; Cao, L.; Wan, Y. Precipitation behaviour during the $\beta \rightarrow \alpha / \omega$ phase transformation and its effect on the mechanical performance of a Ti-15Mo-2.7Nb-3Al-0.2Si alloy. Sci. Rep. 2019, 9, 17628. [CrossRef]

32. Babaei, H.; Levitas, V.I. Finite-strain scale-free phase-field approach to multivariant martensitic phase transformations with stress-dependent effective thresholds. J. Mech. Phys. Sol. 2020, 144, 104114. [CrossRef]

33. Basak, A.; Levitas, V.I. An exact formulation for exponential-logarithmic transformation stretches in a multiphase phase field approach to martensitic transformations. Math. Mech. Sol. 2020, 25, 1219-1246. [CrossRef]

34. Ehsan Esfahani, S.; Ghamarian, I.; Levitas, V.I. Strain-induced multivariant martensitic transformations: A scale-independent simulation of interaction between localized shear bands and microstructure. Acta Mater. 2020, 196, 430-443. [CrossRef]

35. Basak, A.; Levitas, V.I. Matrix-precipitate interface-induced martensitic transformation within nanoscale phase field approach: Effect of energy and dimensionless interface width. Acta Mater. 2020, 189, 255-266. [CrossRef]

36. Babaei, H.; Basak, A.; Levitas, V.I. Algorithmic aspects and finite element solutions for advanced phase field approach to martensitic phase transformation under large strains. Comput. Mech. 2019, 64, 1177-1197. [CrossRef]

37. Basak, A.; Levitas, V.I. Nanoscale multiphase phase field approach for stress- and temperature-induced martensitic phase transformations with interfacial stresses at finite strains. J. Mech. Phys. Sol. 2018, 113, 162-196. [CrossRef]

38. Basak, A.; Levitas, V.I. Finite element procedure and simulations for a multiphase phase field approach to martensitic phase transformations at large strains and with interfacial stresses. Comp. Meth. Appl. Mech. Eng. 2019, 343, 368-406. [CrossRef]

39. Kilmametov, A.R.; Ivanisenko, Yu.; Straumal, B.B.; Gornakova, A.S.; Mazilkin, A.A.; Hahn, H. The $\alpha \rightarrow \omega$ transformation in titanium-cobalt alloys under high-pressure torsion. Metals 2018, 8, 1. [CrossRef]

40. Straumal, B.; Kilmametov, A.; Gornakova, A.; Mazilkin, A.; Baretzky, B.; Korneva, A.; Zięba, P. Diffusive and displacive phase transformations in nanocomposites under high pressure torsion. Arch. Met. Mater. 2019, 64, 457-465.

41. Babaei, H.; Levitas, V.I. Stress-measure dependence of phase transformation criterion under finite strains: Hierarchy of crystal lattice instabilities for homogeneous and heterogeneous transformations. Phys. Rev. Lett. 2020, 124, 075701. [CrossRef]

42. Levitas, V.I. Phase field approach for stress- and temperature-induced phase transformations that satisfies lattice instability conditions. Part, I. General theory. Int. J. Plast. 2018, 106, 164-185. [CrossRef]

43. Straumal, B.B.; Kilmametov, A.R.; Mazilkin, A.A.; Gornakova, A.S.; Fabrichnaya, O.B.; Kriegel, M.J.; Rafaja, D.; Bulatov, M.F.; Nekrasov, A.N.; Baretzky, B.; et al. The formation of the $\omega$ phase in the titanium-iron system under shear deformation. JETP Lett. 2020, 111, 568-574. [CrossRef] 
44. Levitas, V.I. High-pressure phase transformations under severe plastic deformation by torsion in rotational anvils. Mater. Trans. 2019, 60, 1294-1301. [CrossRef]

45. Nakajima, H.; Ishioka, S.; Koiwa, M. Isotope effect for diffusion of cobalt in single-crystal $\alpha$-titanium. Philos. Mag. A 1985, 52, 743-751. [CrossRef]

(c) (

(C) 2020 by the authors. Licensee MDPI, Basel, Switzerland. This article is an open access article distributed under the terms and conditions of the Creative Commons Attribution (CC BY) license (http://creativecommons.org/licenses/by/4.0/). 